\title{
Teatros do silêncio
}

\section{Cassiano Sydow Quilici}

\section{0 prestígio do silêncio}

prestígio que o silêncio adquiriu em diversos projetos artísticos modernos e contemporâneos já foi constatado por diversos autores. ${ }^{1}$ A problematização dos limites da linguagem humana é um tema que pertence a muitas épocas e culturas, mas o modo dela aparecer na arte e no teatro recentes tem diversas peculiaridades. De forma extremamente geral, podemos dizer que as "estratégias do silêncio" na arte atual estão ligadas freqüentemente à constatação de uma degeneração da linguagem cotidiana. As tentativas de explicação desta crise da comunicação são muitas: o impacto dos regimes políticos totalitários e das guerras, a banalização promovida pela cultura de massa, a linguagem "objetificante" decorrente do domínio da técnica, a crise das "grandes narrativas" etc. O fato é que o recurso ao silêncio tornou-se um tema artístico recorrente, não só para denunciar situações político-sociais e expressar dilemas existenciais, como também para propor uma terapêutica da linguagem e da percepção humana. As artes cênicas têm sido particularmente sensíveis a essas questões. A aposta no "enxugamento" ou no voluntário empobrecimento da linguagem, a afirmação de um discurso fragmentário, permeada de "buracos", silêncios e hesitações, a ênfase no não-verbal, são marcas que aparecem no teatro do final do século XIX, e se radicalizam no XX e XXI. O próprio "hermetismo" da "cena contemporânea" pode ser visto como expressão do interesse artístico em se trabalhar nas bordas da linguagem. A fuga da comunicação direta e da compreensão fácil se justificaria na medida em que os signos predominantes na vida social estariam irreversivelmente contaminados pelos clichês e pela banalização.

É certo que, como nos diz Sontag (1987), há um "descontentamento perene" com a linguagem humana, formulada pelas principais civilizações do Ocidente e do Oriente, especialmente no terreno da mística. A experiência do silêncio tem um lugar central tanto na mística cristã quanto nas tradições orientais (taoístas, budistas e sufis, entre outras). Na chamada "teologia negativa" do Cristianismo, a conquista do silêncio interior atesta o desprendimento do

Cassiano Sydow Quilici é professor do Programa de Comunicação e Semiótica da PUC-SP e do Departamento de Artes Cênicas do IA-Unicamp .

1 Ver a esse respeito os ensaios "O Poeta e o Silêncio" e "O Repúdio à Palavra", em Steiner (1988), e "A Estética do Silêncio”, em Sontag (1987). 
mundo dos sentidos, dos pensamentos e das formas, criando as condiçóes necessárias para uma experiência do absoluto. Em autores como Mestre Ekhart e São João da Cruz é no silêncio central da alma que "Deus opera". Silenciar é aprender a mergulhar na "noite escura" (São João da Cruz), desapegando-se radicalmente das sensações, pensamentos, imagens mentais (inclusive das próprias representaçóes de Deus). Ao mesmo tempo, não se trata de negar pura e simplesmente a linguagem, pois esse processo de esvaziamento criaria as condiçóes para a emergência de um outro tipo de discurso, revigorado pela imersão no silêncio. $\mathrm{O}$ silêncio assinalaria assim tanto o limite da linguagem como a condição essencial para a sua renovação.

Mas esta relação entre silêncio e experiência do absoluto, que caracteriza a abordagem mística, torna-se distante numa época como a nossa, fortemente marcada pelo relativismo. Entre nós é mais freqüente que o silêncio apareça como sinal de alguma forma de repressão, censura ou angústia diante da dissolução das referências e ideais (religiosos, científicos, políticos). Um silêncio trágico e pessimista, nem sempre destituído de humor, que não deixa de nos remeter à questão do niilismo no mundo contemporâneo. Por outro lado, existem também diversas tentativas de recuperação de uma arte "metafísica", em que o silêncio é, ao mesmo tempo, motor de uma ascese e condição para emergência de uma experiência do sagrado. Vejamos alguns poucos exemplos nas artes cênicas que nos falam dessas diferentes atitudes.

\section{A fala abafada}

No teatro moderno, a questão do silêncio emerge de forma bastante significativa já na dramaturgia de Tchécov. Para Peter Szondi (2001), as personagens do dramaturgo russo vivem o momento presente numa espécie de "ausência psíquica”. A ação dramática e o diálogo, pontos fundamentais na estrutura do drama clássico, não desaparecem totalmente, mas perdem o vigor, abrindo espaço a um sentimento de tédio que contamina o momento presente. Ao restringirem seu interesse pela vida imediata, as personagens passam a fixar-se em considerações sobre um passado que não pode retornar. As falas são permeadas de "auto-análises resignadas", ditas numa situação coletiva, mas sem figurar propriamente um diálogo. São "quase monólogos" que se justapóem, fortalecendo a impressão de uma solidão essencial, vivida melancolicamente. Na tentativa de compreenderem sua própria situação, as personagens não vão até as últimas conseqüências, apegando-se, ao invés disso, a projetos vagos e nostálgicos. A impotência dos discursos torna o "não-dito" particularmente relevante. As personagens falam, mas tornam-se pequenas diante do tempo da história que não acompanham e do tempo da natureza que as faz envelhecer. A presença silenciosa da natureza muitas vezes se faz presente como pano de fundo ao drama humano, conferindo uma dimensão quase cósmica à cena. ${ }^{2}$

Da perspectiva da encenação naturalista, o "não-dito" nas peças de Tchécov deveria encontrar outros meios de ser evidenciado. Interessará rastrear os significados ocultos das hesitações e elipses discursivas, tornando-os legíveis para o público. Para enfrentar tais desafios, Stanislavski lançou mão do recurso do "subtexto" e das "açôes físicas". O ator deverá construir para si mesmo um texto mental, de modo a explicitar os pensamentos e motivaçóes ligadas à situação dramática. Deste modo, ele poderá preencher internamente os silêncios da fala, explicitando para si mesmo seu sentido oculto. As intenções das personagens aparecerão para o

2 O diretor brasileiro José Celso, comentando a encenação que o Teatro Oficina fez das "Três Irmãs", enfatiza a presença dos ciclos da natureza no texto de Tchécov, chegando a afirmar que descobriu o teatro sagrado com essa peça. A esse respeito, ver Corrêa (1998, p. 230-9). 
público no modo em que o "subtexto" vaza nas pequenas ações e detalhes da atuação. $\mathrm{O}$ que está escondido pelo silêncio das palavras reaparece no comportamento físico da personagem, construído conscientemente pelo ator.

O silêncio aqui se torna o signo de uma dificuldade de dizer, de uma "fala recalcada". Patrice Pavis chamará esse "não-dizer carregado de sentido" de "silêncio decifrável" (Pavis, 1999, p. 360). Subjacente a este tratamento do silêncio existe uma concepção psicológica da personagem como um indivíduo que possui um "subconsciente" que pode ser decifrado pela platéia. A tensão inicial produzida por um discurso que falha é atenuada na medida em que a encenação procura mostrar ao público, por meios não-verbais, a "verdade" da personagem e da situação. $\mathrm{O}$ silêncio tem nesse caso um sentido meramente negativo, de abafamento, subsistindo a pressão de algo reprimido que quer vir à tona. Neste sentido, a encenação cumprirá uma função complementar à da dramaturgia, construindo os sinais e indícios daquilo que foi retirado das falas. As forças e tensões subjacentes que preenchem esse silêncio deverão transformar-se em signos legíveis, compondo um "texto espetacular". ${ }^{3} \mathrm{O}$ encenador constrói discursos paralelos ao discurso verbal, articulando diferentes sistemas significantes para a produção do sentido geral da encenação.

\section{Corpo e imagem}

A exploração das insuficiências do discurso verbal na dramaturgia estimulou novas investigações teatrais no terreno da comunicação corporal. Meyerhold, já na primeira fase do seu trabalho, afirmava que "as palavras não dizem tudo" e que "a verdade das relaçôes humanas está determinada pelos gestos, poses, olhares e silên- cios" (grifo meu). O "novo teatro" deveria saber explorar as tensões e contradiçóes entre a expressão verbal e a corporal. Se a palavra já não diz com clareza, é o corpo que deverá reaprender a se comunicar. Para tanto, a encenação deveria retomar antigas tradiçôes, como a da commedia dell'arte e a dos teatros orientais, com o intuito de recriar uma gramática corporal adequada ao nosso tempo. O "teatro da convenção consciente", proposto por Meyerhold, exige que o ator aprenda a utilizar "convençôes" gestuais, construídas e fixadas. O corpo não deverá expressar-se de modo vago e involuntário. Ele tem de se formar numa linguagem capaz de ser operada com precisão. O corpo deve ser um emissor de signos que lança novas luzes sobre a situação dramática, explicitando contradições fundamentais da trama. A "convenção consciente" contrapóe-se também ao ilusionismo naturalista, revelando ao espectador o caráter "artificial" da construção teatral.

Há uma espécie de "vontade de verdade" nesse desejo de fazer o corpo "dizer" o que está oculto pelo silêncio verbal. Trata-se ainda de buscar um teatro que deseja revelar os significados ocultos do drama. Mas, ao mesmo tempo, reconhece-se que, se o corpo comunica, não o faz exatamente da mesma forma que o discurso verbal. Meyerhold afirma a capacidade dos gestos e movimentos expressarem, por exemplo, as motivações profundas das personagens. Hoje, diríamos que a linguagem corporal é mais permeável às "pulsões", memórias e experiências pouco acessíveis à consciência. $\mathrm{O}$ discurso do corpo pode se estruturar a partir desse terreno movediço, trazendo à tona o que não encontra espaço na lógica linear do discurso verbal.

O corpo é também um elemento fundamental para a construção visual e imagética das cenas. As imagens podem se comunicar de uma maneira mais sintética e instantânea com

3 A noção semiológica de "texto espetacular" tenta dar conta da articulação das diferentes linguagens que compõem a encenação. Ver Pavis (2001, p. 408-9). 
o público. Como constatou a psicanálise a partir dos estudos sobre a linguagem dos sonhos, a expressão plástica e visual costuma ser mais aberta às conexões associativas do que as linguagens abstratas, permitindo os processos de condensação de significados. A construção de signos teatrais através da linguagem corporal e visual estimularia uma diversidade de leituras e interpretaçôes, exigindo também uma postura mais ativa do espectador. Meyerhold, contrapondo-se ao excesso de detalhes da cena naturalista, procurou explorar imagens sugestivas e incompletas, que exigissem um trabalho imaginativo do espectador.

\section{Hieróglifos do vazio}

Antonin Artaud trará novas contribuições para o aprofundamento dessas questôes. Nos seus textos sobre o teatro balinês, Artaud constata a existência de uma "linguagem física baseada nos signos e não mais nas palavras”, que se expressa nas complexas utilizações dos gestos, dos figurinos, da música e do espaço. No entanto, esses signos (que ele chamará de "espirituais"), apesar de serem construídos de modo preciso, não podem ser facilmente traduzidos numa linguagem lógica e discursiva. A linguagem não-verbal não está ali, necessariamente, para ser interpretada em palavras ou para gerar múltiplas leituras. $\mathrm{O}$ teatro não existe apenas para ser "lido". A questão passa a ser outra. Os hieróglifos do teatro balinês propõem a nossa convivência com um certo vazio de significado. Um vazio que não nos deixa indiferentes, mas nos afeta. Trata-se de acolher experiências que não são necessariamente apreensíveis pelas palavras:

"Todo verdadeiro sentimento é na verdade intraduzível. [...] Todo sentimento forte pro- voca em nós a idéia de vazio. $\mathrm{E}$ a linguagem clara que impede esse vazio impede também que a poesia apareça no pensamento. É por isso que uma imagem, uma alegoria, uma figura que mascare o que gostaria de revelar tem mais significação para o espírito do que as clarezas proporcionadas pelas análises das palavras" (Artaud, 1999, p. 79).

A condição necessária para o surgimento da poesia é este convívio com o vazio que permeia a linguagem e o pensamento. "Sentese no Teatro de Bali um estado anterior à linguagem e que pode escolher sua linguagem: música, gestos, movimentos, palavras" (idem, p. 65; grifo meu). Quando Artaud menciona aqui um "estado anterior à linguagem" não está propondo exatamente uma regressão a uma forma de consciência "pré-lingüística", mas a sustentação de um "recuo" em relação à linguagem, um desprendimento interior em relação às palavras e aos pensamentos. Os espaços silenciosos, experiências ainda não codificadas, manchas de consciência, que emergem nas frestas e nas fissuras da linguagem, são assim valorizados. É a partir dessa experiência que se "escolhe" a linguagem, ou seja, a linguagem germinará desse vazio. Os signos buscados por Artaud mascaram esse vazio, não exatamente no sentido de escondê-lo, mas de resguardá-lo e protegê-lo contra as pretensões da razão de traduzi-lo numa representação. O uso da palavra "vazio" em Artaud remete muitas vezes às metafísicas orientais, especialmente ao taoísmo. ${ }^{4}$ Alude a uma experiência da "não forma", que pode se desdobrar em múltiplos modos de manifestação:

"A cultura é um movimento do espírito que vai do vazio às formas, e das formas regressa ao vazio, ao vazio semelhante à morte. Ser culto é queimar formas, queimá-las a fim de

4 A esse respeito, ver a conferência que Artaud deu na cidade do México, em 1936, "O Teatro e os Deuses" (Artaud, 1975). 
se atingir a vida. É aprender a equilibrar-se dentro do incessante movimento das formas que vão sendo sucessivamente destruídas" (Artaud, 1975, p. 37).

$\mathrm{Na}$ visão de Artaud, a "verdadeira cultura" é aquela que mantém a conexão com o vazio e o informe. Como no taoísmo, 5 esse vazio não pode ser completamente apreendido por representações discursivas, que tenderiam a constrangê-lo num conceito. A "não-forma" pode ser apenas "figurada", através de imagens e alusões. Mas a opção por uma linguagem alusiva e simbólica não é necessariamente uma opção pela imprecisão. Para Artaud, o que impressiona no teatro balinês é a estruturação rigorosa, quase matemática, da encenação, que se articula em torno de um núcleo obscuro, que nunca se deixa desvelar completamente. Os balineses teriam devolvido às convenções teatrais o seu "valor superior". Se as convenções não se referem apenas a uma realidade concreta, devendo desencadear uma experiência do sagrado, elas não o fazem de modo vago. O que Artaud celebra no teatro oriental é a tradição viva que o sustenta, presente nos seus métodos de treinamento e na gramática da encenação. Uma tradição que alia uma minuciosa elaboração formal com o mais vivo impulso para o sagrado.

\section{Signos e impulsos}

Jerzy Grotowski retomará a idéia de que a experiência do silêncio relaciona-se com a construção de signos precisos e de partituras de atuação. A estruturação minuciosa de roteiros de ação, que exigem uma grande concentração para serem executados, permitiria ao ator o refinamento da sua sensibilidade. Investigando a execução da "linha de ações físicas" o ator passará a perceber os impulsos que originam as ações. Perceber os "impulsos" significa experimentar a ação no seu nível "microfísico". Os impulsos ocorrem no interior do corpo, na sua profundidade, antes que a ação se desdobre no espaço. Grotowski às vezes localiza esse interior em alguma parte anatomicamente identificável (coluna vertebral, por exemplo), mas chega a dizer também que "impulso" é um conceito complexo não referido apenas ao domínio corporal. A consciência dos impulsos subjacentes às ações implica na experiência de uma "corrente viva" que atravessa o corpo, e que será canalizada pelos signos construídos pelo ator. Os signos só se tornam vivos se estão conectados à experiência energética que o ator tem de suas ações. O público, por sua vez, será afetado não só por aquilo que pode ler no espetáculo, mas também pela presença viva do ator em cena. Ao definir o teatro como um "encontro", Grotowski não pensa apenas na comunicação através de signos, mas numa "comunhão" que passa pela vivência das intensidades produzidas na cena.

Em vários momentos, no vocabulário de Grotowski, o "além da linguagem" é o campo das manifestaçôes primárias do "vital" e do "orgânico’. O silêncio (como limite da linguagem) é aqui preenchido por uma espécie de "energética”. As metáforas utilizadas para aludir a esse campo de experiência remetem quase sempre a uma espécie de "vitalismo". Aquilo que ultrapassa e transborda a linguagem são os fluxos vitais, os substratos orgânicos das ações. Mesmo abdicando do realismo, trata-se ainda de revelar a "vida" em cena. Não a vida mediada pelos costumes, a vida filtrada pelo ambiente social e psicológico, como no caso da estética naturalista, mas a vida oculta e "bloqueada" pelas convenções, e que só poderia vir à tona através de uma outra linguagem, que deixa-se ser atravessada pelos impulsos orgânicos. Trata-se de alcançar

5 O que o taoísmo chama de "tao sem nome" é irredutível a qualquer representação. 
um silêncio habitado, não por "subtextos" ou conteúdos psicológicos recalcados, mas por fenômenos sutis ligados ao corpo e às sensações.

A percepção desses fenômenos estaria ligada também ao desenvolvimento do que Grotowski chama de "testemunha muda de si mesmo". O performer deve aprender a agir e ao mesmo tempo a observar-se, mas sem verbalizar mentalmente essa observação. $\mathrm{O}$ exercício deste tipo refinado de atenção silenciosa, abriria as portas para um outro modo de percepção do corpo, das ações e de si mesmo. O trabalho de Grotowski aqui tenta se aproximar de antigas tradições espirituais em que a atenuação do fluxo interno de pensamentos tem um lugar central.

\section{A "esfera da morte"}

Uma outra perspectiva de abordagem do silêncio no teatro moderno aparece com o movimento simbolista e certos desenvolvimentos posteriores. Nessas propostas, a morte passa a ser o ponto em torno do qual se expõe o drama humano. Numa cultura "desencantada" e secular, a "finitude"6 é evocada como o fator que recoloca o homem diante de limites extremos. Num mundo "desabitado pelos deuses", o questionamento metafísico pode reaparecer na confrontação do homem com a angústia que a morte suscita. O dramaturgo belga Maurice Maeterlinck tirou máximo partido dessa situação. Em seus dramas, a aproximação da morte tem o poder de revelar diferentes formas de ilusão. "Presença" quase sempre invisível, a morte se imiscui silenciosa e lentamente nas tramas da vida, através de "sinais" que são mais ou menos captados pelas diferentes personagens. ${ }^{7}$ A entrada em cena desta visitante inesperada exige tam- bém uma reformulação dos procedimentos clássicos de construção do drama. Os acontecimentos exteriores dão lugar a atmosferas, em que predomina a não-ação. Os conflitos cotidianos são relativizados frente à confrontação com a possibilidade do desaparecimento das personagens. Todos os acontecimentos e conflitos mundanos encontram-se subjugados de certo modo a uma questão mais abrangente: a dissolução da vida no desconhecido. Nasce daí a idéia de um "drama estático", cujo desenvolvimento obedece a uma dinâmica distinta da progressão dialética dos conflitos. Ao mesmo tempo, o diálogo cotidiano dá lugar a falas hesitantes, contaminadas de silêncios e vazios, aproximandose de um registro lírico e musical.

As conseqüências desse tipo de drama para o trabalho do ator não foram menos notáveis. A proximidade da morte coloca em xeque o próprio lugar do corpo na arte teatral. $\mathrm{O}$ incômodo de Maeterlinck e Gordon Craig com a presença demasiado ostensiva do ator no palco abriu novas perspectivas de se pensar os modos de estar em cena. O corpo como sede de automatismos, hábitos e paixões corriqueiras tornase um problema para uma arte que aspira ao sublime. Esse corpo cotidiano e "grosseiro" deve "morrer", ou seja, deve ser "desinvestido" para que possa nascer uma nova forma de expressão. O exercício da imobilidade torna-se um dos caminhos de realização dessa morte para os hábitos da vida comum. $\mathrm{O}$ ator deve aprender a desmontar as gesticulaçôes e movimentos automáticos para então construir um "grande véu de convenções sintéticas" (Maeterlinck), tornando sua presença um "símbolo", uma ponte que liga a vida ao mistério da morte. A linguagem dos gestos nasce aqui desse mergulho no silêncio e na não-ação.

6 O tema da "finitude" da existência humana recebeu diversas elaborações filosóficas na primeira metade do século XX, especialmente em Heidegger.

7 Um bom exemplo desse tratamento dramático da morte encontra-se na peça "A Intrusa", de Maeterlinck. 
Ao mesmo tempo, o teatro de marionetes revela-se uma fonte riquíssima de novas metáforas para se pensar o ator. Em oposição à linguagem do naturalismo, que enfatiza sempre a colocação da "vida" em cena, as marionetes evocariam o inorgânico e a morte. E quando a vida se torna demasiadamente investida pelas ambições humanas, a morte aparece, às vezes, como uma "última fronteira", uma potência questionadora e renovadora da vida. Para Craig, a marionete contrapõe-se à patética figura do ator escravo das paixões comuns. Símbolo de uma realidade sobre-humana, "descendente dos antigos deuses de pedra dos templos", a marionete evocaria uma atitude serena diante das vaidades e inquietudes do corpo e da alma. Daí a força de sua presença e a beleza de seus gestos. Para o ator, ela pode tornar-se um modelo superior, um arquétipo da perfeição e do corpo em estado de êxtase. O silêncio aqui deve penetrar o corpo e os gestos, para retirá-los do turbilhão da "pequena vida", marcada pelo habitual.

$\mathrm{O}$ encenador polonês Tadeusz Kantor aprofunda a investigação das relações entre a morte e o processo criativo, reformulando algumas questôes do teatro simbolista a partir de novas referências (dadaísmo, construtivismo, Meyerhold, entre outras). Esta preocupação torna-se particularmente relevante a partir da encenação do espetáculo "A Classe Morta" (1975), quando Kantor passa a aprofundar sua pesquisa do "espaço da memória" e do teatro de "comentários íntimos". Essas investigações se desdobram até o seu último espetáculo, "Hoje é dia do meu aniversário" (1990). A questão do silêncio se recoloca aqui a partir do "recurso à morte, à vacuidade, à pura aparência, à ausência de qualquer mensagem" (manifesto "O Teatro da Morte"). Quando se abre à "esfera da morte", o teatro pode trazer a vida em cena sob uma nova perspectiva. $\mathrm{O}$ termo "esfera da mor- te", que surge no programa do espetáculo "Que morram os artistas", não designa a apresentação da morte em cena como um "fato dramático e violento". Trata-se, em vez disso, de se trabalhar artisticamente com a ação corrosiva e silenciosa do "morrer". ${ }^{8}$ Kantor pretendia utilizar-se desse "elemento coercitivo" quase como a estrutura do espetáculo. $\mathrm{O}$ permanecer na "orla de alguma coisa que não podemos tocar nem nomear" torna-se uma espécie de ato inaugural do teatro. É neste "lugar" que serão "encontrados" (e não construídos ou fabricados) as personagens e objetos, como "sinais que provém de algum lugar". O que é "encontrado" não foi propriamente "procurado". O artista, penetrando a "esfera da morte", torna-se disponível a algo que "vem ao encontro". Assim Kantor se refere à personagem Veit Stoss, de "Que Morram os Artistas": "Ele veio sozinho. Ninguém o chamou". Podem emergir também as "chapas fotográficas da infância”, memórias que às vezes tentamos ordenar, mas que possuem uma dinâmica própria, irrompendo em cena de modo desordenado e anárquico.

Kantor buscará no ator justamente este "homem habitado pela morte", contaminado pelo infinitamente distante, e que, ao mesmo tempo, volta-se para a comunidade humana portando uma estranha e terrível "mensagem". Mensagem que não pode ser reduzida à expressão lingüística, nem a uma dilatação da presença corporal do ator. Os atores de Kantor, próximos das figuras de cera e dos manequins, são "presenças esvaziadas", expressōes da "realidade no seu mais baixo escalão", sem função, significado ou utilidade para o mundo. Paradoxalmente, tornam-se entidades insólitas que nos fascinam e aterrorizam, remetendo-nos a nossa condição mortal e, ao mesmo tempo, possibilitando-nos uma abertura para o desconhecido. $\mathrm{O}$ ator-manequim é marcado pelo selo da

8 Abre-se aqui a possibilidade de se estabelecer uma relação com a noção de "pulsão de morte", que para a psicanálise trabalha de um modo "silencioso". 
morte, tornando-se um "duplo", um portador de uma consciência superior alcançada na consumação da vida. Para o mundo banalizado dos "vivos", ele emerge das trevas de uma "noite silenciosa", como uma "imagem" de infância, capaz de impressionar profundamente nossa memória. Nessa arte que nasce entre os vivos e os mortos, o destino humano é medido e avaliado numa "escala implacável e definitiva, a escala da Morte".

\section{Observações finais}

Deste panorama inicial, bastante incompleto, destacaremos algumas linhas de reflexão. As "retóricas do silêncio" abordadas referem-se não só ao "limite da linguagem" como também às fronteiras entre os diversos tipos de linguagens. $\mathrm{O}$ silêncio pode guardar aquilo que não é capturado no registro verbal, reter uma "intensidade" que, por sua vez, é deslocada para um outro domínio de expressão (corporal, visual etc) . Como afirma Lyotard (1985), aquilo que foi excluído do sistema lingüístico pode passar para uma extensão gestual e visual, ganhando uma "figura- ção". As pesquisas relacionadas ao corpo e a construção imagética da cena não só ampliaram nossa consciência sobre sistemas de signos nãoverbais como também fizeram emergir novas questôes sobre o modo do teatro afetar o espectador. O teatro não oferece apenas algo para ser visto e interpretado pelo público, mas também experiências de difícil codificação. $\mathrm{O}$ "teatro dos signos", que se oferece a múltiplas leituras, pode conviver e confrontar-se com um "teatro das energias", que mobiliza intensidades, sensações e fluxos que resistem às leituras racionais. Já a evocação da morte em alguns artistas (Craig, Maeterlinck, Artaud, Kantor) parece sugerir uma outra modalidade de silêncio, que não se confunde apenas com a exaltação da experiência energética. Permanecer na "orla do que não se pode tocar nem nomear" é despregar-se tanto das "representações discursivas" quanto das experiências sensoriais. Esse vazio pode penetrar todo o fenômeno cênico, retirando algo de seu poder de fascinação espetacular, mas oferecendo-nos em troca um espaço de liberdade, onde os processos de criação poderiam encontrar fontes mais profundas. 


\section{Referências bibliográficas}

ARTAUD, Antonin. O teatro e seu duplo. São Paulo: Martins Fontes, 1999.

. Mensagens revolucionárias. Lisboa: Engrenagem, 1975.

CORRÊA, José Celso Martinez. Primeiro ato: cadernos, depoimentos, entrevistas. Org. de Ana Helena Camargo de Staal. São Paulo: Editora 34, 1998.

KANTOR, Tadeusz. “O teatro da morte”. Sala Preta, n. 2, 2002.

. Que morram os artistas. Trad. de Márcia de Barros. Disponível em <www.fabricasaopaulo. com.br>.

KOBIALKA, Michal. A journey through other spaces - essays and manifestos, 1944-1990. Los Angeles: University of California Press, 1993.

LYOTARD, Jean François. Discours, figure. Paris: Klincksieck, 1985.

MEYERHOLD, Vsevolod. Teoria teatral. Madri: Fundamentos, 1986.

PAVIS, Patrice. Dicionário de teatro. São Paulo, Perspectiva, 1999.

RICHARDS, Thomas. Travailler avec Grotowski sur les actions physiques. Paris: Actes Sud, 1995.

SONTAG, Susan. A vontade radical. São Paulo: Companhia das Letras, 1987.

STEINER, George. Linguagem e silêncio. São Paulo: Companhia das Letras, 1988.

SZONDI, Peter. Teoria do drama moderno. São Paulo: Cosac \& Naif, 2001. 